\title{
Agriculture and Food Sector in Slovakia and Czech Republic
}

\author{
L’udmila BARTÓKOVÁ \\ Technical University of Košice, Košice, Slovakia \\ ludmila.bartokova@tuke.sk
}

\begin{abstract}
The input-output analysis is based on the analysis of the various multipliers. Together with the analysis of the coefficients of intermediate production it allows to evaluate the structure of the economy, the impacts of changing demand in various sectors in national economy. IOT framework also offers a very detailed image of intersectorial economic linkages, either backward or forward oriented. It helps to understand the impacts of the changing structure of the national economy. The aim of this paper is to look closely at the evolution of two selected industries (agriculture and food production) in Slovak and Czech Republic over the period 2000-2014. We compared the evolution of technical, allocation and import coefficients as well as output, input and import multipliers in case of these two industries in order to verify the similarities in their development.
\end{abstract}

Keywords: IOT Analysis, Multipliers, Sectors, Slovakia, Czech Republic.

\section{Introduction}

The basic structure of an input-output table (IOT) is the transaction matrix where rows represent suppliers and columns represent users. By converting the initial monetary values in the transactions matrices to ratios (coefficients), it is possible to examine the underlying system of interactions and interdependencies. This paper uses the basic IOT methodology in order to assess the importance of output, input and import multipliers for selected sectors. With regards to general trend of decrease of importance in the traditional sectors, we have chosen two, so-called basic sectors agriculture and food production. The analysis should illustrate how these two sectors evolved and whether their position and importance in Slovakia and Czech Republic changed in the years following 2000 . We would also like to verify the stability and similarity in their evolution.

\section{$2 \quad$ Literature review}

The fundamental information used in input-output analysis concerns the flows of products from each industrial sector, considered as a producer, to each of the sectors, 
itself and others, considered as consumers. This basic information, from which an input-output model is developed, is contained in an interindustry transactions table.

The rows of such a table describe the distribution of a producer's output throughout the economy. The columns describe the composition of inputs required by a particular industry to produce its output. [4] The necessary data are the flows of products from each of the sectors (as a producer/seller) to each of the sectors (as a purchaser/buyer). These flows (interindustry or intersectoral) are measured for a particular time period (usually a year) and in monetary terms. The intersectoral flows of products and services are registered, simultaneously by origin and by destination. [1] Based on these linkages, it is possible to evaluate the structure of the economy, or overall impacts of changing demand in various sectors in national economy. Inputoutput framework evaluates two kinds of economic linkages between sectors, i.e. backward linkages, representing demand side, and forward linkages, representing supply side. [2] The analysis of the strengths of BLs and FLs allows to identify the most important sectors in the economy. The study of BLs and FLs allows to determine which industries can be considered as key industries in terms of demand and supply. [6, 7] In case of an open economy, the imported products should be also taken into account. Increases in production will equally generate additional imports to support it. [10]

\section{$3 \quad$ Methodology}

Using the demand-side model, different kinds of input-output multipliers can be generated, i.e. output multipliers, input multipliers, income multipliers, employment multipliers and import multipliers. They can be viewed as summary measures used to estimate the likely effects of economic change. Various multipliers generally remain fairly stable over time. Technological change does not occur very rapidly in most industries therefore it is possible to obtain reasonable results for the latest year even though the latest IOTs may be a few years old. [3]

Assume a national economy is divided into " $\mathrm{n}$ " sectors. If "Xi" represents the total output of sector "i", "Yi" the total final demand for sector "i's" product, and "Zij" the inter-industry flows between sectors, we can describe economy by following set of equations [4]:

$$
\begin{gathered}
X_{1}=Z_{11}+Z_{12}+\ldots+Z_{1 j}+\ldots+Z_{1 n}+Y_{1} \\
X_{2}=Z_{21}+Z_{22}+\ldots+Z_{2 j}+\ldots+Z_{2 n}+Y_{2} \\
X_{i}=Z_{i 1}+Z_{i 2}+\ldots+Z_{i j}+\ldots+Z_{i n}+Y_{i} \\
\ldots \\
X_{n}=Z_{n 1}+Z_{n 2}+\ldots+Z_{n j}+\ldots+Z_{n n}+Y_{n}
\end{gathered}
$$


When we divide the flows of input from " $\mathrm{i}$ " to " $\mathrm{j}$ " ("Zij") by the total outputs of "j" ("Xj"), we obtain ratios of input to output, so-called technical coefficients. According to Pissarenko [5], they also represent cost structure of the industry. The equations can be also expressed in matrix notation as $\mathrm{X}=\mathrm{AX}+\mathrm{Y}$. We obtain $\mathrm{X}=(\mathrm{I}-\mathrm{A})^{-1}$, where the inverse matrix $(I-A)^{-1}$ is also referred to as Leontief inverse matrix L (e.g. [2]:

$$
L=(I-A)^{-1}
$$

By adding up each column vector of the matrix L, we obtain simple output multipliers (SOMs). The simple output multiplier can be equally viewed as the backward linkage of the particular sector, [6,4] The output multiplier measures the effects of one monetary unit change in the final demand for each sector on total output of all sectors (including the sector itself). Assessing impacts of imports requires knowing the vector of import coefficients "im", then calculating the matrix $\mathrm{im}(\mathrm{I}+\mathrm{A})^{-1}$, and lastly adding up column vector of this matrix. Simple import multipliers (SIMps) can be defined as the total change in imports (endogenous variable) when the final demand (exogenous variable) changes by one unit. [3, 8]

The IO tables equally allow studying the supply-side perspective, i.e. the relationship between output and primary inputs. This type of analysis provides data for allocations coefficients and input multipliers (SIMs) of the economy, reflecting the forward linkage of the particular sector. [6, 4] However, in this case the coefficients and multipliers are calculated using the row vectors.

Once calculated, output and input multipliers (backward and forward linkages) can be used to determine the key sectors of the economy. According to Rasmussen (1956, in [6]) if normalised values of both multipliers are higher than 1, the sectors can be classified as key sectors. If only one of the values is higher than 1 , the sector is either backward or inward oriented, meaning it serves as an important purchaser or supplier for other industries of analysed economy.

\section{$4 \quad$ Results}

With regards to the limited extent of this paper, we decided to analyse only the evolution of two production sectors that correspond to Agriculture and Food production - sectors $\mathrm{A} 01$ and $\mathrm{C} 10-12$ according to the International Industrial Classification, revision 4 (ISIC Rev.4). We used data from the WIOD Database covering the period 2000-2014. [9, 11]

The choice of sectors can be linked to the general trend of decline of domestic production in these sectors even though they can still be considered as basic sectors of each economy. Therefore we would like to verify what is the place and position of these sectors in selected countries; whether they underwent some significant changes. We would also try to look for similarities in their evolution between countries.

Firstly we looked closely at the coefficients that represent intermediate production, i.e. technical coefficients (for output), allocation coefficients (for input) and import coefficients (for import). The next step was the analysis of the output, input and 
import multipliers. And lastly we used statistical tests in order to verify the similarity of the evolution of analysed times series.

As we can see on Fig. 1 (sector of agriculture, A01), the highest values of coefficients can be observed for the allocation coefficients (symbol line) that exceed the values for technical coefficients (black line) as well as the import coefficients (grey line). It means that the agriculture sector serves rather as the supplier of inputs than the purchaser of the intermediate production. In case of Slovak Republic (first graph) we can clearly see the decrease of importance in domestic production (both demand and supply side view, i.e. black and symbol line). This is compensated by the increase in import coefficients (grey line), meaning that Slovakia is becoming more and more dependent on the imports of inputs from abroad. The values and evolution of these coefficients for Czech Republic (second graph) seems more stable than in case of Slovakia.
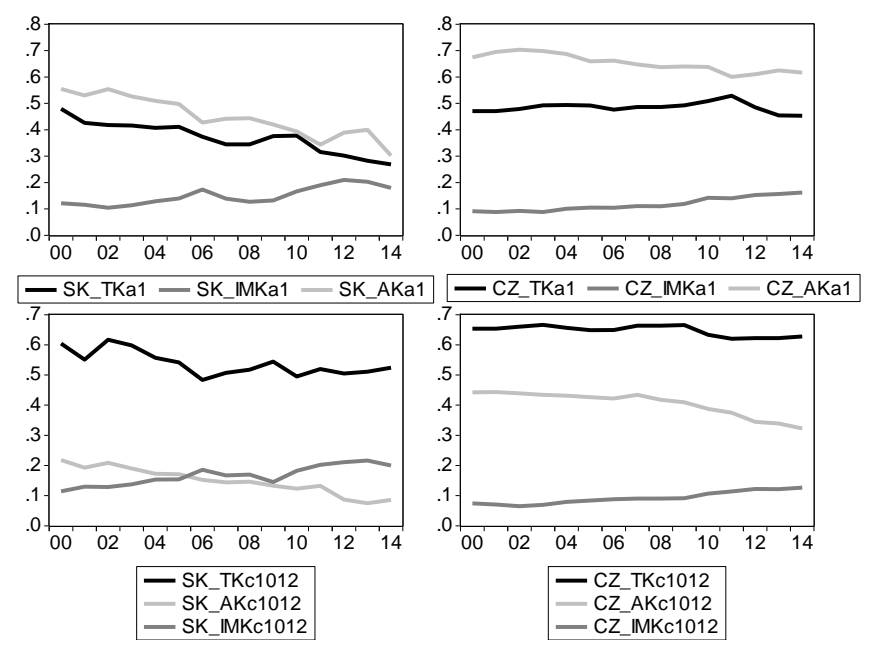

Fig. 1. Technical, allocation and import coefficients, sector A01 (left) and sector C1012 (right). [11]

The evolution of values in Food production (sector C1012) is slightly different (Fig. 1 - third and fourth graph). Over this period, the values of technical coefficients (black line) exceeded the other two for both economies. The values were from the range 0.50.7; the lowest values were observed in case of Slovakia (third graph) where we can also see a slight decrease in values as well as a distinctive growing trend for import coefficients (grey line). Again, it signifies the increase of the dependency of domestic food industry on the foreign suppliers. Evolution in Czech Republic (fourth graph) seems again more stable; however, the increase for import coefficients is also present even though it is less steep.

In order to see the overall positions of these sectors, we should also analyse how the values of the multipliers evolved over the observed period. The Fig. 2 shows the boxplots of output and input multipliers for both sectors and both countries. Here we 
can see several interesting facts. In case of Slovakia, distributions of values for both multipliers are almost identical for agriculture and rather similar (when we omit few far outlier values) for food production. The evolution in A01 can be considered as mostly stable, as indicated by the symmetric distribution of values and closeness of median and mean. In C1012 the mean and median are different, indicating some fluctuations in the evolution of the values.

In Czech Republic the values for A01 multipliers are slightly higher than in Slovakia. What is more, the output multipliers are lower than the input multipliers. This suggests a higher importance of the supplies from the industry. However, in case of C1012 sector, the output multipliers highly exceed the input multipliers. The values thus confirm the fact that the agriculture production serves mainly as inputs to other industries while food industry, on the other hand, produces mainly for the final consumption.

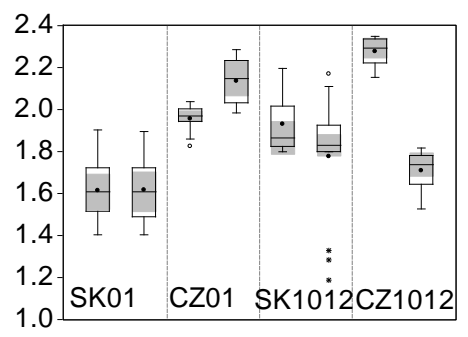

Fig. 2. Output (left) and input (right) multipliers, sector A01 and C1012. [11]

The next set of boxplots on Fig. 3 depicts the distribution of values of import multipliers for both sectors. The left side of the graphs illustrates the situation for agricultural production.

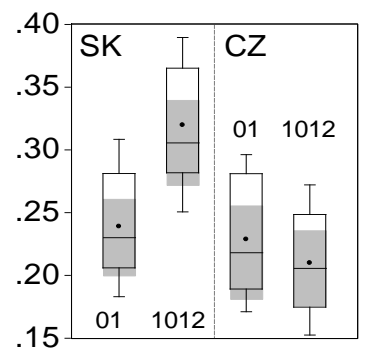

Fig. 3. Import multipliers, sector A01 and C1012 for Slovakia (left) and Czech Republic (right). [11]

Here we can see that the countries are rather similar with the majority of the values from the range $(0.20-0.26)$. The lowest values of import multiplier appear in case of Czech Republic $(0.18-0.24)$. Values of import multipliers for Slovakia are almost twice as high $(0.27-0.36)$. This shows that Slovakia imports more food production that Czech Republic. 
Graphs on Fig. 4 show the evolution of normalised backward (nBL) and forward linkages (nFL) in sector of agriculture and food production (normalised output and input multipliers). Values of nBLs and nFLs higher that 1 indicate the orientation of the sector either backward (strong demand linkage) or forward (strong supply linkage). If both linkages exceed 1, this sector can be considered as key sector to the economy. As we can see on the following graphs, the agricultural production (a01) could be considered as key until around 2005-2006 for both Slovakia and Czech Republic.
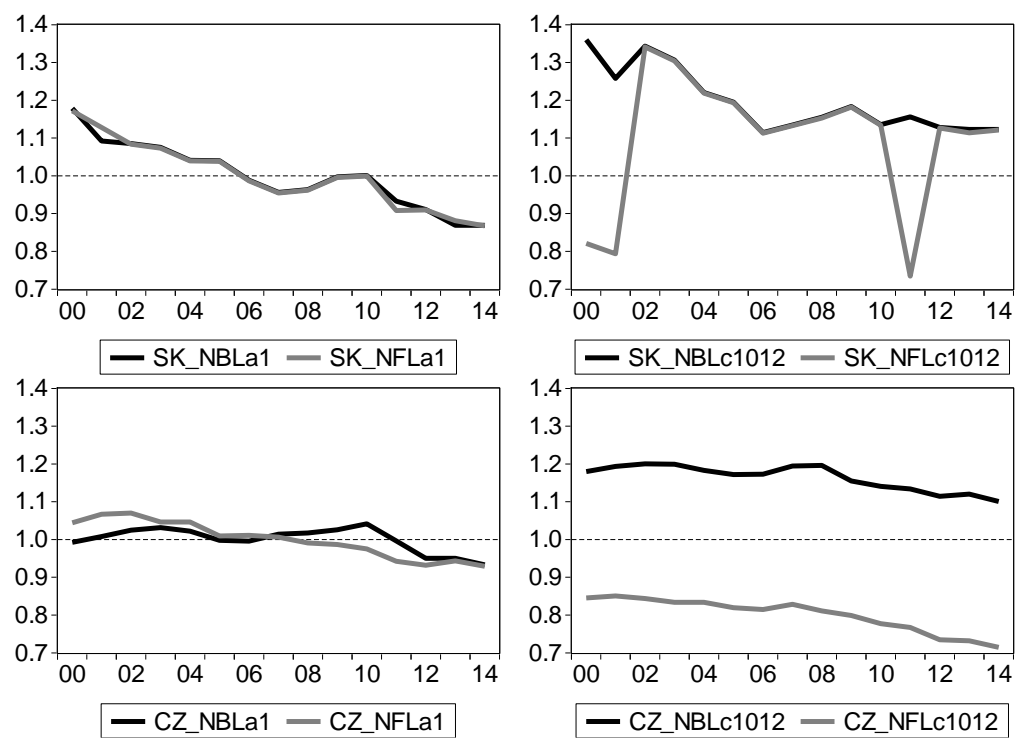

Fig. 4. Normalised BLs and FLs, sectors A01 and C1012 for Slovakia (left) and Czech Republic (right). [11]

The nBLs and nFLs for food (c1012) production show different characteristics of this sector. While in case of Czech Republic this sector is clearly backward oriented and rather stable, in Slovakia the evolution is marked with several fluctuation. However, in general it could be considered as one of the key sectors for most of the observed years. The evolution of both sectors seems to be more stable in Czech Republic.

The last part of the analysis consisted of the statistical testing in order to verify the similarity in evolution of the values of time series. We used Mann-Whitney-Wilcoxon test of equality of medians between series. It enables to test whether the distributions of the series are identical or very similar and is usually use in case of two independent data samples that do not influence each other. This test also does not require that the time series are normally distributed. The null hypothesis $\mathrm{H} 0$ is that the distributions of two tested series are identical. We chose the 0.05 significance level. In case HO is rejected, we assume that evolutions of tested variables in different countries can be considered neither as identical nor similar. 
In each case we compared Slovak and Czech time series. The following table presents the results of the tests. In all cases when the HO hypothesis was confirmed (the identic or very similar development of the time series), it was marked by $\mathrm{H} 0$ in the table. If $\mathrm{H} 0$ was rejected, the table cell was marked $\mathrm{H} 1$ meaning that two time series were different in their evolution.

Table 1. Tests for equality of medians between time series - comparison between countries [11]

\begin{tabular}{|c|c|c|c|c|c|c|c|}
\hline & SK & Som c1012 & Som a01 & Sim c1012 & Sim a01 & Simp c1012 & Simp a01 \\
\hline $\mathrm{CZ}$ & & H1 & H1 & H1 & H1 & H1 & Ho \\
\hline & SK & Tk c1012 & Tk a01 & Ak c1012 & Ak a01 & Impk c1012 & Impk a01 \\
\hline CZ & & $\mathrm{H} 1$ & H1 & $\mathrm{H} 1$ & H1 & H1 & H1 \\
\hline
\end{tabular}

According to the test, the null hypothesis was accepted only in the case of import multiplier and only for the agricultural sector. This confirmed similarities only in this one case, the evolution for other times series cannot be considered identic, as the tests did not confirm the similarities in their distribution. We accept the alternative hypothesis; the evolution of other multipliers as well as three coefficients of intermediate production did evolve neither in the same nor in the similar way.

Table 2. Tests for equality of medians between time series - comparison within countries [11]

\begin{tabular}{|c|c|c|c|c|c|c|c|}
\hline & SK & Som c1012 & Som a01 & Sim c1012 & Sim a01 & Simp c1012 & Simp a01 \\
\hline $\mathrm{CZ}$ & & H1 & H1 & H1 & H1 & H1 & H0 \\
\hline & SK & Tk c1012 & Tk a01 & Ak c1012 & $\mathrm{Ak}$ a01 & Impk c1012 & Impk a01 \\
\hline $\mathrm{CZ}$ & & H1 & H1 & H1 & H1 & H1 & H1 \\
\hline
\end{tabular}

As for the coefficients, the results should mainly correspond to the results of testing for multipliers. However, here the similarities were not confirmed for none of the tested pairs of coefficients.

\section{Conclusion}

The aim of this paper was to look closely at the evolution in the food (c1012) and agricultural (a01) sector in two of V4 countries, namely Slovakia and Czech Republic. We analysed the evolution of technical, allocation and import coefficients as well as the output, input and import multipliers over the period of $2000-2014$.

The comparison of the coefficient values confirms that in general the agriculture sector serves rather as the supplier of inputs that the purchaser of the intermediate production, as confirmed by higher values of allocation coefficients (in comparison with technical and import coefficients). Slovak Republic was marked by the significant decrease of importance in domestic production that was compensated by the increase in import coefficients. Czech Republic is still less dependent on the 
imports of foreign inputs. Increase in domestic dependence on imports appeared also for Slovak food sector.

As for the stability of both sectors, we could see that the ranges of multiplier values are different, with higher differences for Czech Republic. The distribution of values of import multipliers showed that Slovakia import more food production than Czech Republic.

The analysis of backward and forward linkages showed that the food production in case of Czech Republic is clearly backward oriented with a stable evolution. In case of Slovakia the evolution was marked with several fluctuations. However, in general, it could be considered as one of the key sectors for most of the observed years.

The last part of the analysis consisted of statistical testing of similarity of evolution in time series. We used the Wilcoxon - Mann - Whitney test for equality of medians between series. Firstly we compared the evolution of Slovak and Czech time series, then the evolution of time series within each country. The test results indicate similarities between Slovak and Czech economy only to a certain extent (agricultural sector). However there were no similarities between time series of food production.

In future it would be interesting to carry on this analysis with the comparison of other industries.

Acknowledgements. The data and the knowledge presented in this paper were obtained as a result of the Research Project "Economic implications and perspectives of the participation of the Slovak Republic in the process of production activities fragmentation within Global Value Chains". (VEGA/1/0961/16).

\section{References}

1. D'Hernoncourt, J., Cordier, M., and Hadley, D.: Input-output multipliers-specification sheet and supportting material. Spicosa Project Report. (2011), http://www.coastalsaf.eu/output-step/pdf/Specification\%20sheet\%20I_O_final.pdf, last accessed 2017/09/26.

2. Lábaj, M.: Štrukturálne aspekty ekonomického rozvoja - Slovenská ekonomika v globálnych súvislostiach. Vydavatel'stvo Ekonóm, Bratislava (2014).

3. McLennan, W.: Australian national accounts: Introduction to input-output multiplier. (1995), http://www.abs.gov.au/AUSSTATS/abs@.nsf/DetailsPage/5246.0198990?OpenDocument, last accessed 2017/09/30.

4. Miller, R. E., Blair, P. D.: Input - Output analysis. Foundation and Extentions. 2nd edn. Cambridge University Press, New York (2009).

5. Pissarenko, D.: Basics of input-output analysis, http://demetrix.sourceforge.net/resources/2003_02_20_ioAnalysis/ioAnalysis.pdf, last accessed 2017/10/14.

6. Reis, H., Rua, A.: An input-output analysis: Linkages vs leakages. International Economic Journal, 23(4), 527-544 (2009), DOI: 0.1080/10168730903372323.

7. The world input-output database (WIOD): Contents, Sources and Methods, http://www.wiod.org/publications/source_docs/WIOD_sources.pdf, last accessed 2017/10/14. 
8. Trinh, B., Le Hoa, P., Giang, B., C.: Import multiplier in input-output analysis. Journal of science, economics and business 25(5), 41-45 (2009).

9. United Nations Statistics Division - Classifications Registry: Detailed structure and explanatory notes, https://unstats.un.org/unsd/cr/registry/regcst.asp?Cl=27, last accessed 2017/10/14.

10. Wixted, B., Yamano, N., Webb, C.: Input-output analysis in an increasingly globalised world. OECD Science, Technology and Industry Working Papers 7, 3-46 (2006), DOI: $10.1787 / 18151965$.

11. World Input Output Database: National Input Output Tables, http://www.wiod.org/database/niots16, last accessed 2017/10/19. 